\title{
Magneto-optical properties of barium ferrite sputtered films
}

\author{
R K KOTNALA \\ Materials Division, National Physical Laboratory, New Delhi 110012, India \\ MS received 13 October 1991 \\ Alstract. Barium ferrite thin films with perpendicular anisotropy were grown on (111) \\ oriented GGG substrate by rf diode sputtering method. Their magnetic properties were \\ measured. Faraday rotation was measured in the wavelength range 460-800 nm for such \\ sputtered thin filtns. These films were found quite suitable for magneto-optical recording \\ applications.
}

Keywords. Magtneto-optical rotation; Faraday totation; barium ferrite; ff sputtering; X-ray diffracton; vibrating sample magnetometer.

\section{Introduction}

Today, engineers and scientists involved in designing and developing recording systems must choose between advancing old technologies and developing new technology to achieve higher recording densities. During the first twenty years of history magnetic recording relied heavily on particulate iron-oxide media and bulk ferrite materials and recording heads. Today there is serious contention between proponents of particulate, metallic thin films and sputtered oxide-recording media. Nevertheless new recording technologies such as optical recording are making inroads into the market place. These technologies which use Cocussed laser beams to access bits can today be made with much narrower trackwidths than the conventional magnetic recording and bit densities of the order of $10^{8} / \mathrm{cm}^{2}$ have been demonstrated. Using magneto-optic media such optical recording technology (Gomi et al 1988; Kucera et al 1989) could be made erasable and have all the features of present-day magnetic recording as well as the high bit densities of optical recording.

Barium ferrite thin films have a large magneto-optic rolation (Corradi et al 1989; Kaneko et al 1987 ) and are expected to be used as the next generation magneto-optical (MO) disk materials. It is a hexagonal ferrite with magneto-plumbite structure and the films from this material are expected to be better perpendicular magnetic films because of their large crystalline anisotropy. Such oxide materials exhibit high corrosion resistance to attain high reliability.

In this study, we have successfully grown barium ferrite thin films by if sputtering. Faraday rotation and magnetic properties of barium ferrte thin films have been measured. Such films exhibit strong magneto-optical effect in the short wavelength region. The value of Faraday rotation measured for some of the films was $0.72 \times 10^{4} \mathrm{deg} / \mathrm{cm}$ at $530 \mathrm{~nm}$.

\section{Experimental}

Barium ferrite thin films were prepared by if diode sputtering in pure argon gas. The substrate used for the film growth was (111)-oriented $\mathrm{Gd}_{3} \mathrm{Ga}_{5} \mathrm{O}_{22}$ (GGG) single 
Tabie 1. Spultering conditions tor barium territe thin film.

\begin{tabular}{ll}
\hline Base pressure & $5 \times 10^{-7}$ torr \\
Digcharge current & $270 \mathrm{~mA}$ \\
Argon gas pressure & $50 \mathrm{~m}$ torr \\
Depositiont rare & $210 \mathrm{~A} / \mathrm{min}$ \\
Substrate temperature & $590^{\circ} \mathrm{C}$ \\
Substrate & GGG (111) \\
\hline
\end{tabular}

Table 2. Composition, thickncss, Faraday rotation and mignctic properties of a cypical sample $\mathrm{B} a \mathrm{~F}+46$.

\begin{tabular}{|c|c|}
\hline Composition & $\mathrm{Ba}_{0.92} \mathrm{Fe}_{12} \mathrm{O}_{19}$ \\
\hline Thickness & $0.6 \mathrm{~mm}$ \\
\hline Faraday rotation & $0.72 \times 10^{4}$ deg \\
\hline$M_{s}$ (perpendicular to film plane) & $362 \mathrm{en11} / \mathrm{cm}^{3}$ \\
\hline$H_{c}$ (perpendicular to film plates & $14000 \mathrm{e}$ \\
\hline
\end{tabular}

crystal $\left(2.5 \times 20 \mathrm{~mm}\right.$ in size) which were heated up to $580^{\circ} \mathrm{C}$ during sputtering. Ceramic targets were used with the stoichiometric barium ferrite compositions of $\mathrm{BaFe}_{12} \mathrm{O}_{19}$ and $\mathrm{Ba}_{1 \cdot 14} \mathrm{Fe}_{12} \mathrm{O}_{19}$ (barium overdosed). Table 1 shows typical sputtering conditions. The chemical composition of the films was analysed by an induction coupled plasma (ICP) method. Magnetic properties such as coercive force $\left(H_{t}\right)$ and saturation magnetization $\left(M_{s}\right)$ of the films in petpendicular direction were measured by vibrating sample magnetometer. Table 2 represents the composition, thickness, Faraday rotation and magnetic properties of a typical sample out of the many samples prepared. Faraday rotation of the films was measured at room temperature by polarization modulation method using a monochromator.

\section{Results and discussion}

X-ray diffraction analysis (figure 1) showcd that the films were polycrystalline with magnetoplumbite type barium ferrite structure exhibiting a preferred orientation along C-axis with the presence of $(006),(008),(200)$ and (220) lines. Most of the films showed saturation magnetization values in perpendicular direction to the plane of the film. which was close to the value of butk barium ferrite material as shown in figure 2 . Saturation magnetization value $362 \mathrm{em} / \mathrm{cc}$ in thin film was obtained from overdosed barium target, as barium ferrite film grown by this target gave stoichiometry close to $\mathrm{BaFe}_{12} \mathrm{O}_{19}$ composition (table 2).

To confirm the magneto-optical behaviour of the thin films Faraday rotation spectra of different barium ferrite films were measured. The peak value of Faraday rotation in $\mathrm{Ba}_{0.92} \mathrm{Fe}_{12} \mathrm{O}_{19}$ thin film was as large as $0.72 \times 10^{4} \mathrm{deg} / \mathrm{cm}$ at $530 \mathrm{~nm}$ wavelength. 


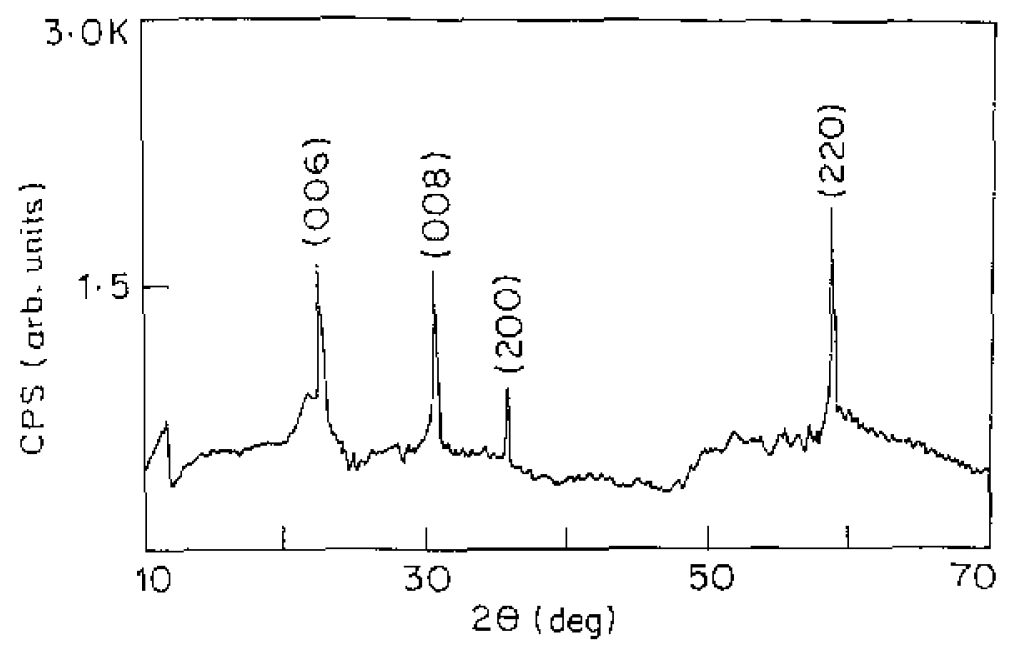

Figure 1. X-ray diffraction pattern of $\mathrm{Ba}_{\mathrm{L}_{0.92}} \mathrm{Fe}_{12} \mathrm{O}_{19}$ film.

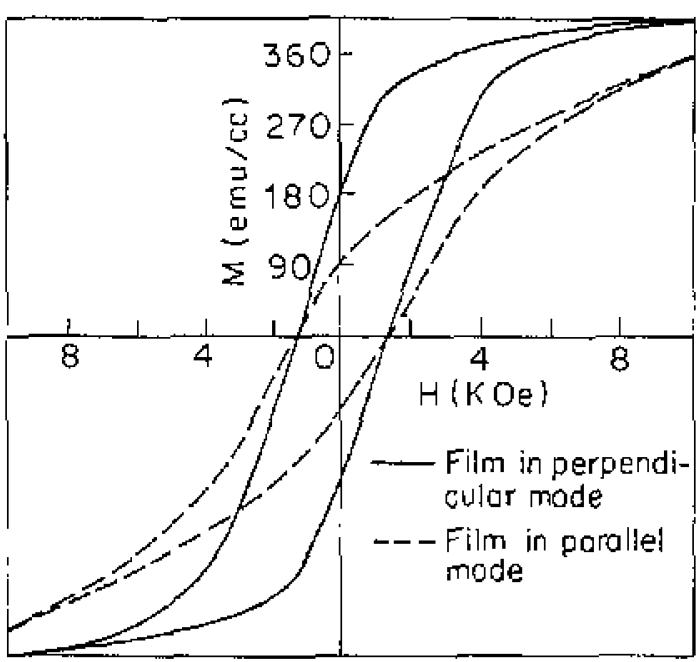

Figure 2. B-H loop in perpendicular and parallel mode for the $\mathrm{Ba}_{0,92} \mathrm{Fe}_{12} \mathrm{O}_{19}$ film.

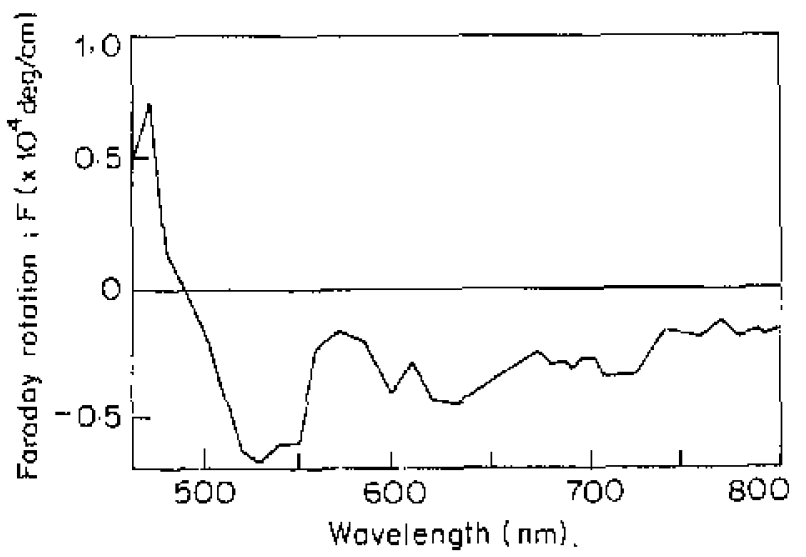

Figure 3. Faraday rotation of the barium fertite thin film in the wavelength range $460-800 \mathrm{~nm}$. 


\section{Conclusions}

Good quality barium ferrite thin films showing magnetization in perpendicular direction to the plane of the films were grown. These films which were magneto-optically active were useful for magneto-optical recording.

\section{Acknowledgements}

The author is thankful to Dr B K Das for encouragement. Thanks are also due to Prof, $M$ Abe of the Tokyo Institute of Technology, Tokyo for the help rendered in some of the measurements.

\section{References}

Corradi A R, Speliotis D E, Bottoni G, Candolfo D, Cecchetti A and Masoli F 1989 IEEE Trans. Magnet. 254066

Gomi M, Satoh K and Abe M $1988 \mathrm{Jph}$. J. Appl. Phys, $27 \mathrm{~L} 1536$

Kaneko Y, Sawado Y, Ohuni P. Miyamoto I and Watada A 1987 J pn. J. Appl Phys. Stupl 2623

Kucera M. Bok J and Nitsch K 1989 Solid State Commun, 691117 